\title{
HÁ VIDA NA ESCOLA E ESCOLA NA VIDA: ALGUMAS PROVOCAÇÕES A PARTIR DO PROJETO DE LEI "ESCOLA SEM PARTIDO"
}

\author{
THERE IS LIFE IN SCHOOL AND THERE IS SCHOOL IN LIFE: SOME \\ PROVOCATIONS ABOUT THE DRAFT LAW" SCHOOL WITHOUT POLITICAL \\ PARTY"
}

\author{
HAY VIDA EN LA ESCUELA Y HAY ESCUELA EN LA VIDA: ALGUNAS \\ PROVOCACIONES SOBRE EL PROYECTO DE LEY "ESCUELA SIN PARTIDO \\ POLÍTICO”
}

\author{
Rosinei Ronconi Vieiras \\ Doutor em Educação \\ Instituto Federal de Educação Ciência e Tecnologia do Espírito Santo - Ifes. \\ Colatina, ES - Brasil \\ rosineirv@hotmail.com \\ Bruna Neitzel Sepulcri \\ Mestra em Educação

Resumo: O artigo em questão tem como objetivo principal problematizar e analisar a relação de congruência permanente entre escolasociedades, visando potencializar um processo de aprendizagem que seja/esteja voltado para a produção de outras relações, valorizando a pluralidade de experiências e conhecimentos existentes e constantes entre esses espaços. Nessas discussões, pensadores como Morin (1991), Santos (2010), Alves (2008) e Maturana (2009) correspondem a alguns dos intercessores teóricos com os quais procuramos nos envolver. Tendo como enfoque a proposta de lei denominada "Escola sem Partido", que visa retroceder e "robotizar" o processo educacional e seus sujeitos, discute-se a relação da racionalidade hegemônica moderna, com sua perspectiva dualista e fragmentária de entendimento da realidade, com essa proposta de lei, cuja lógica comporta e implica a possibilidade de neutralidade da escola em relação ao que se passa na sociedade. Além disso, o artigo aborda, também, a necessidade urgente de um questionamento permanente da ideia dicotômica e reducionista com que é tratada a relação da escola com a sociedade, propondo, assim, a recusa a qualquer proposta/projeto ou mesmo modelo que submeta ou limite a liberdade do pensamento no ambiente escolar.

Palavras Chave: Educação. Sociedade. Escola Sem Partido.

Abstract: This article mainly aims at problematizing and analyzing the permanent congruence relation between schools and societies, aiming to develop a learning process which is oriented towards the production of other relationships, valuing the plurality of existing and constant experiences and knowledge in these spaces. It problematizes the proposal of the Draft Law called "School without Political Party", that aims to move back and to "robotize" the educational process and its subjects. Then, this article discusses the relation of modern hegemonic rationality, with its dualistic perspective of understanding the reality, observed through this proposal whose logic includes the possibility of neutrality of the school in relation to what is happening in society. The theoretical framework is based on authors such as Morin (1991), Santos (2010), Alves (2008) and Maturana (2009). Also, this study highlights the urgent need for a permanent questioning on the dichotomous and reductionist idea with which school and society are treated, as well as proposes a refusal of any proposal/project that submits or limits the freedom of thought in the school environment.

Key words: Education. Society. School Without Political Party.

Resumen: Este estudio tiene como objetivo principal problematizar y analizar la relación de congruencia permanente entre escuelas y sociedades, con el objetivo de potencializar un proceso de aprendizaje que esté o se concentre en la producción de otras relaciones, valorando la pluralidad de experiencias y saberes existentes y constantes entre estos espacios. Estas discusiones se basan en pensadores como Morin (1991), Santos (2010), Alves (2008) y Maturana (2009), que corresponden a algunos de los intercesores teóricos con los que buscamos involucrarnos. Centrándonos en la propuesta de ley denominada "Escuela sin Partido Político", que busca retroceder y "robotizar" el proceso educativo y sus sujetos. Así, se discute acá la relación entre la racionalidad hegemónica moderna, con su perspectiva dualista y fragmentaria de entender la realidad, por medio de esta propuesta cuya lógica incluye e implica la posibilidad de neutralidad de la escuela en relación a lo que ocurre en la sociedad. Además, el artículo también aborda la urgente necesidad de un cuestionamiento permanente de la idea dicotómica y reduccionista con la que se trata la relación de la escuela con la sociedad, proponiendo así el rechazo de cualquier propuesta / proyecto, o incluso modelo, que presente o limite la libertad de pensamiento en el entorno escolar.

Palabras clave: Educación. Sociedad. Escuela Sin Partido Político.

Para citar - (ABNT NBR 6023:2018)

VIEIRAS, Rosinei Ronconi; TRISTÃO, Martha; SEPULCRI, Bruna Neitzel. Há vida na escola e escola na vida: algumas provocações a partir do projeto de lei “Escola Sem Partido”. Eccos - Revista Científica, São Paulo, n. 56, p. 1-13, e8544, jan./mar. 2021. Disponível em: https://doi.org/10.5585/eccos.n56.8544. 


\section{Introdução}

Há algumas décadas, o pensador austríaco Ivan Ilich publicou uma obra intitulada Sociedade sem Escolas. Nela, o autor traça uma crítica ao processo de escolarização institucionalizada, defendendo uma "desescolarização". Sem entrar no mérito dessa produção, o nosso ensaio procura se compor com a realidade que temos, não deixando de problematizar o que está posto à educação contemporânea e de potencializar aquilo que pensamos ser interessante para a produção/criação de outros mundos possíveis.

Uma das problematizações que acreditamos ser necessária, em nosso tempo, é a da dualidade cartesiana. A literatura em torno dessa dicotomia com que se operou a modernidade é bastante vasta e com variados enfoques. No entanto, em grande parte dos estudos, o pensamento cartesiano é tomado como o precursor de um modelo que na atualidade opera por dualismos e que, "hoje", se apresentando como problemático apesar de no momento de sua concepção não ser assim entendido.

A força desse pensamento se constitui de tal forma que, atravessando o tempo - o tempo em que se constituiu -, passa a ser atribuída a uma determinada maneira de perceber/entender a realidade. O paradigma hegemônico ocidental, por exemplo, fruto desse pensamento, provocou diversos outros dualismos, que se enraizaram nos discursos e em muitas maneiras de ser, ver e fazer presente nas sociedades contemporâneas, algo que, para alguns autores, se constituiu numa forma de racionalidade.

Consequentemente - e até mesmo inconscientemente - repetidas vezes, de diferentes formas e nas mais variadas esferas e/ou instâncias, reproduzimos, em nossos afazeres cotidianos, os mecanismos dessa racionalidade operando de forma dicotômica e/ou disjuntiva sem nos darmos conta.

Esse modo de entendimento da realidade, na qual se procura estabelecer e/ou situar uma determinada "verdade", se expressa dentre outras formas na/pela linguagem. Nesse caso observamos e entendemos que a conjunção “ou” é uma das maneiras com a qual se expressa tal perspectiva: "certo ou errado"; "bom ou mau"; "desenvolvido ou subdesenvolvido"; "natureza ou cultura"; "teoria ou prática"; "mente ou corpo"; "dentro ou fora"; "escola ou sociedade", dentre tantas outras.

Situando essa forma de racionalidade no âmbito educacional e movendo-nos para o ambiente das escolas, este artigo tem como objetivo problematizar a relação/articulação existente entre sociedades e escolas (dentro-fora), visando a potencializar um processo de 
aprendizagem que seja/esteja voltado para a produção de outras relações, valorizando a pluralidade de experiências e de conhecimentos existentes e constantes entre esses espaços.

Reconhecemos, também, o risco que corremos em ficarmos atados naquilo que pretendemos nos afastar ou questionar, que é justamente a dualidade, a disjunção e a crença de que é possível "murar" e isolar a escola das intempéries e/ou do fervilhar da vida em sociedade. Ou seja, dos tantos momentos marcados pelo contato com o outro, pelo afeto, pela troca de experiências, enfim pelo complexo emaranhado de redes que constituem nossos saberes e nossas histórias/experiências de vida.

\section{Movimentos plurais "dentrofora" das escolas}

Quando aproximamos a racionalidade hegemônica de alguns discursos proferidos para a educação, torna-se ainda mais relevante a problematização que propomos neste artigo, como a de que a escola não acompanha as tendências/mudanças da sociedade, ou o recente caso em que se situa uma proposta no âmbito legislativo de isolar e/ou "neutralizar" a escola das discussões políticas - um projeto com pretensões de lei, chamado "Escola Sem Partido". Tanto em uma quanto em outra ideia está a crença de que escola e sociedade correspondem a dois espaços distintos/separados e independentes.

Na primeira ideia, a escola é considerada defasada em relação à sociedade, enquanto, no segundo, está presente a ideia de que a comunicação e a intercomunicação entre ambas podem e devem ser controladas. Ou seja, ambas as ideias apresentam uma perspectiva dualista de entendimento das realidades que atravessam os cotidianos das escolas e de outros espaços da sociedade.

Esse discurso também é atravessado por outras diferentes questões, como, por exemplo, a da violência, em que os muros físicos das escolas parecem isolá-la dos acontecimentos em sua volta. Há toda uma lógica que procurou - e ainda procura - "proteger" a escola do que se considera ser o "mal" da sociedade e que, portanto, deve ser mantido afastado, não podendo adentrar no espaço escolar, onde o que é "bom" e "correto" está se aprendendo e se desenvolvendo.

Não estamos inferindo que, por exemplo, se uma escola está localizada em um bairro considerado violento, ela vai, de forma mimética, reproduzir a violência. Nossa problematização vai no sentido de questionar a capacidade dos muros/cercas e qualquer outro 
mecanismo/dispositivo em isolar ou ainda neutralizar o que está acontecendo fora do espaço físico da escola.

Ao longo da última década, temos acompanhado nas grandes mídias o pavor que funcionários/as e alunos/as de escolas públicas do Estado do Rio de Janeiro têm passado durante períodos de trocas de tiros nas comunidades. Realidade essa que, infelizmente, não é apenas fluminense.

Nessa dolorosa realidade, os gritos, os tiros e o medo não ficam isolados pelos muros físicos que cercam as escolas. Queiramos ou não, a violência adentra as salas de aula, seja na forma de sons, de imagens e/ou de experiências vivenciadas pelos sujeitos que a frequentam.

Logo, por mais que a intencionalidade presente nessa lógica de separabilidade esteja/seja imbuída de valores protetivos/defensivos, acreditamos ser impossível tal fato se concretizar efetivamente. Difícil a proteção quanto à violência e impossível o isolamento desses espaços em relação ao que se passa fora deles.

Desse modo, partimos do pressuposto que os muros representam mais uma fronteira ${ }^{1}$, constantemente transpassada, do que uma estrutura rígida de separação ou de isolamento. Assim, constituem-se como algo que tem poucos efeitos reais sobre qualquer tentativa de proteção e de secção.

Além disso, todos/as que compomos a comunidade escolar estamos impregnados/as de nossos processos de subjetivação, como infere Carvalho:

O professor, assim como o aluno, ao chegar à escola, não abandona os mitos, as crenças, as ideias próprias de seu grupo social e nem conseguiria fazê-lo, pois carrega consigo processos de subjetivação e/ou formas de subjetividade de algum modo instituídos a partir de um sistema sociopolítico, econômico e cultural (2004, p. 29).

Acreditamos que a relação que o espaço da escola possui com a sociedade é de interações e retroações, atuando uma com a outra de forma não só congruente, mas também recursiva, afinal o espaço escolar insere-se na sociedade e esta se presentifica no espaço escolar.

Ampliando a discussão, o biólogo Humberto Maturana, ao realizar um estudo a respeito da linguagem e da relação da aprendizagem com nossa corporalidade, nos propõe pensar que "[...] o aprender tem a ver com as mudanças estruturais que ocorrem em nós de

\footnotetext{
${ }^{1}$ Trazemos aqui a perspectiva de Edgar Morin ao descrever sobre a dupla identidade de uma fronteira, que ao mesmo tempo representa fechamento e abertura: "Toda fronteira, inclusive a membrana dos seres vivos, inclusive a fronteira das nações, é barreira e, ao mesmo tempo, o local de comunicação e de troca. Ela é lugar da dissociação e da associação, da separação e da articulação. Ela é o filtro que ao mesmo tempo obstrui e deixa passar. É através dela que se estabelecem as correntes osmóticas que impede a homogeneização" (MORIN, 2013, p. 252).
} 
maneira contingente com a história de nossas interações" (MATURANA, 2009, p. 60). Dessa forma, podemos entender que o ser humano - ou mesmo a escola - vive em congruência com todo o seu meio.

Nesse sentido, nas problematizações supra expostas acreditamos ser pertinente a colocação realizada por Maturana (2009, p. 64):

\begin{abstract}
Quando estamos em interações recorrentes na convivência, mudamos de maneira congruente com nossa circunstância, com o meio, e num sentido estrito nada é obra do acaso, porque tudo nos ocorre num presente interconectado que se vai gerando continuamente como uma transformação do espaço de congruências a que pertencemos. Ao mesmo tempo, nada do que fazemos ou pensamos é trivial nem irrelevante, porque tudo o que fazemos e pensamos tem consequências no domínio das mudanças estruturais a que pertencemos.
\end{abstract}

Com essas considerações e a partir das fundamentações teóricas dos autores, torna-se arriscado afirmar que a escola se situa numa realidade distinta e isolada e que não acompanha as mudanças sociais, como têm se multiplicado os discursos que apontam para o atraso da escola em relação aos avanços tecnológicos da sociedade.

A escola, muitas vezes erroneamente taxada como instituição secular que não avançou no tempo, vai sendo desqualificada para o "preparo" dos estudantes. Afirma-se que suas práticas pouco evoluíram e o seu formato continua nos moldes de outrora.

Quanto a esse aspecto, pensamos e nos aproximamos da professora Nilda Alves, que ao ser questionada, durante uma entrevista, a respeito de algumas críticas quanto ao fato de a escola não acompanhar os avanços da sociedade, respondeu:

O que eu acho é que isso é impossível. Antes se dizia que a escola tinha muros que a fechavam do resto da sociedade. É uma grande invenção do início do século XIX, mais precisamente da Escola Nova, e que nós repetimos até o fim como se fosse "verdade verdadeira" e como se isso fosse possível. Nós todos, cada um de nós que vai para a escola, vai com tudo aquilo que aprendeu fora da escola, com tudo o que acredita, com o que faz. Obviamente, a escola nunca teve muros, a escola avança como avança toda a sociedade, com os dramas da sociedade, com as dificuldades da sociedade, com a incapacidade de dar soluções a problemas graves que a sociedade tem[...] (ALVES, 2008).

Compartilhamos desse pensamento de que entre escola e sociedade não existem "muros" que as separam. Como a autora afirma em outras produções, todos estamos "dentrofora" da escola (ALVES, 2010). Ou seja, tudo o que vivemos, aprendemos e/ou ensinamos está encarnado em nós e nas tantas redes de conhecimentos e significações presentes em diferentes contextos. Por isso, 
[...] precisamos compreender que os muros das escolas são meras criações imaginárias, mas não indicam o que existe, no que se refere às relações entre as múltiplas e diversas redes educativas e as escolas: precisamos compreender que vivemos todos dentrofora das escolas e que o que é aprendidoensinado nas tantas redes de conhecimentos e significações em que vivemos entra em todos os contextos, porque encarnado em nós (ALVES, 2010, p. 03).

Compreendendo a escola como viva, no sentido de estar constantemente em movimento e conectada com o seu tempo, afastamo-nos de qualquer discurso que afirma sua paralisação perante o tempo. Somos a escola, assim como somos a sociedade. Dito isso, cabe questionar se as mudanças ou os avanços reivindicados para a escola, no sentido de estar atrasada em relação à sociedade ou aos modos de vida social, se justificam e/ou possuem algum sentido.

Não estamos afirmando que mudanças não sejam necessárias ou que não ocorram, mas é importante analisarmos se o que temos cobrado da/para a educação é coerente. As autoras Nilda Alves e Regina Leite Garcia (2008) inferem que o discurso sobre a "crise da escola" deve ser recolocado na perspectiva de uma crise global ética, cultural, social, institucional, econômica e de paradigmas que não dão conta da complexidade do mundo atual. Nesse sentido, a escola representa apenas um dos inúmeros contextos/realidades que refletem a crise da racionalidade ocidental hegemônica presente em nossa sociedade.

Ampliando as colocações realizadas, consideramos serem pertinentes os estudos desenvolvidos pelo pensador francês Edgar Morin, que, ao se envolver com a noção em torno da complexidade, estuda os processos inter e intraculturais e sua relação com o conhecimento e a sociedade, apontando para o fato de que

[...] Cultura e sociedade encontram-se em relação geradora mútua, e, nesta relação, não esqueçamos as interacções entre indivíduos, que são eles próprios portadores/transmissores de cultura; estas interacções regeneram a sociedade, a qual regenera a cultura (MORIN, 1991 p. 17).

Essa relação entre cultura e sociedade traz uma profunda implicação para se pensar a escola/educação. Assim, os indivíduos presentes nesse processo carregam em sua memória/corpo a cultura que alimenta e é alimentada pelo conhecimento que tanto o indivíduo e a sociedade possuem. Esse processo “[...] nos sugere que há um tronco comum indistinto entre conhecimento, cultura e sociedade" (MORIN, 1991, p. 18).

Tal concepção suscita a possibilidade de que o nosso pensamento sobre determinado assunto está intimamente ligado à nossa cultura e ao conhecimento que dela possuímos, influenciando em nossa percepção sobre o real e a visão de mundo, e que, sendo o 
conhecimento produto e produtor de cultura, sua única certeza é o campo de possibilidades que se apresenta diante do conhecimento adquirido.

Com esses pressupostos, que representam também um posicionamento político do educador/pesquisador/a, questionamos: Existe distância entre o que se pensa na sociedade e o que se pensa na escola? Qual seria a relação entre o que se pensa/discute/pratica na sociedade com o que se pensa/discute/pratica na escola? Quando analisamos determinadas práticas escolares, consideramos o contexto (sócio espaço temporal) cotidiano vivido pelos sujeitos daquela realidade na qual estão imersos?

Tais questionamentos não esperam por respostas, principalmente prontas e acabadas, mas procuram ampliar as discussões e/ou provocar outros olhares para a relação "escolasociedade".

\section{A escola como espaço de encontro}

[...] o conhecimento das classes populares, construídos no cotidiano de suas vidas, vai sendo negado na escola, como o "não saber", embora esteja lá e apareça por impertinência, o tempo todo (GARCIA e ALVES, 2008, p. 74).

Com as mesmas inquietações das autoras, o sociólogo Boaventura de Sousa Santos (2010), retomando algumas perguntas formuladas há bastante tempo por Rousseau (1971), nos provoca as seguintes problematizações:

\footnotetext{
Há alguma razão de peso para substituirmos o conhecimento vulgar que temos da natureza e da vida e que partilhamos com os homens e mulheres da nossa sociedade pelo conhecimento científico produzido por poucos e inacessíveis à maioria? Contribuirá a ciência para diminuir o fosso crescente na nossa sociedade entre o que se é e o que se aparenta ser, o saber dizer e o saber fazer, entre teoria e a prática? (ROUSSEAU, 1971 apud SANTOS, 2010, p. 07).
}

Problematizar questões elementares como as formuladas por Rousseau, por exemplo, é fundamental para superar certas dicotomias e fragmentações que envolvem a percepção do distanciamento entre a sociedade e a escola. Esta, apesar de valorizar o conhecimento científico, não consegue evitar os encontros e seus respectivos choques/embates com o conhecimento pautado nas vivências dos coletivos, do senso comum.

Acreditamos, portanto, retomando a ideia da fronteira, que os muros rígidos e as severas tentativas de organização do espaço são, também, incapazes de separar o conhecimento oficial do senso comum, fruto da sabedoria popular. São nesses espaços permeáveis que as disciplinas curriculares se encontram com os conhecimentos populares indisciplinares, plurais e contextualizados. 
As problematizações trazidas até aqui nos incitam a realizar algumas colocações acerca do projeto de lei "Escola Sem Partido", um projeto que, já em seu título, passando por todo seu texto e contexto, como também pelas narrativas de seus precursores ${ }^{2}$, quando se limitam a criticar, punir e banalizar os/as profissionais das escolas, se apresenta incoerente.

Diferente do que afirma seus defensores, não é um projeto que privilegia a pluralidade do/no ensino, mas sim que possui caráter moralista e conservador, que pune e censura determinados conhecimentos produzidos coletivamente pelas experiências compartilhadas "dentrofora" das escolas.

Se o projeto, com suas propostas conservadoras e antidemocráticas, for aprovado, terão as escolas que se organizarem a fim de atender apenas os currículos já instituídos como se isso fosse possível -, com os componentes curriculares e seus respectivos conteúdos engendrados por uma "grade curricular", coibindo a pluralidade e a diversidade de pensamento. É importante lembrar que a própria composição das propostas curriculares prescritas se constituiu a partir de uma relação de poder que objetivou/objetiva atender demandas de grupos sociais específicos. Corroborando com essa linha de pensamento, Garcia e Alves (2008) observam que essa escolha “[...] privilegiava aspectos morais que levassem à manutenção da autoridade nas mãos de quem sempre a teve, servindo para formar pessoas subordinadas a ordens sociais prescritas" (GARCIA e ALVES, 2008, p. 69).

Entende-se que a composição de uma proposta curricular nunca é neutra ${ }^{3}$, afinal a determinação dos conhecimentos que poderiam/podem entrar na escola é fruto de uma escolha realizada buscando o que é considerado conveniente ser aprendido pelos educandos em um determinado contexto histórico-social.

Diferentemente do que apregoa os defensores da "Escola Sem Partido", não há - e nunca houve - neutralidade ou pureza na educação ou em qualquer outro setor/instância da sociedade. Somos constituídos pelas experiências que partilhamos cotidianamente, sendo impossível a produção de ideias e de projetos desinteressados ou desvinculados daquilo que somos e em que acreditamos.

As tendenciosas propostas do projeto parecem querer combater as discussões que são privilegiadas e que compõem a pauta de reivindicações de determinados grupos minoritários.

\footnotetext{
${ }^{2}$ No Brasil, essa proposta foi iniciada por um advogado chamado Miguel Nagib, cuja trajetória está intimamente ligada com organizações vinculadas a setores empresariais e/ou do mercado. Surgida em 2004, ganha proeminência somente em 2014 com a apresentação de projetos de lei para o Estado do Rio de Janeiro, e atualmente as discussões têm se ampliado.

${ }_{3}^{3}$ Descrevendo processos dominantes que permitiram organizar a escola atual, Garcia e Alves (2008, p. 72) falam da escolha dos conhecimentos que adentrariam as escolas como conhecimentos oficiais, resultando em uma hierarquização disciplinar: "Existem, assim, aqueles saberes dignos de serem aprendidos e que, por isso, são colocados no alto, e aqueles que não devem ou não precisam ser aprendidos, e, por isso, são colocados na parte baixa de uma rígida hierarquia.".
} 
Aliás, frisa-se, o próprio nome da proposta é partidário, afinal propor uma escola "sem" partido por si só é uma maneira de tomar partido ou agir politicamente de acordo com convicções que se consideram coerentes ou que se acredita ser "a" verdade.

Algumas questões dentro dessa proposta nos chamam a atenção, principalmente pelos seus absurdos. Uma é quanto ao fato de acreditar que, por medida de lei ou por imposição coercitiva de uma ideia, as escolas seguirão a "cartilha" proposta pelo projeto.

Uma outra questão se refere à própria natureza do fato, isto é, tal proposta chegar ao ponto de precisar ser discutida e debatida em um nível político mais elevado. Isso por si só já demonstra um alerta para o conservadorismo que nos espreita e procura se impor pela legitimação e/ou institucionalização do projeto.

O que não podemos é retroceder ao ponto de ver cerceada a liberdade de expressão e de comunicação. Pensar que essa proposta é neutra e que preza pela imparcialidade, como seus criadores querem sugerir, seria no mínimo ingênuo como também ardiloso, pois zelar por uma suposta "neutralidade" e "imparcialidade" em tempos de crise ética/moral na política é algo bem-quisto à primeira vista. Até mesmo o seu nome foi muito bem escolhido - "Escola Sem Partido" ou "Escola Livre" -, pois soa agradável aos ouvidos mais desavisados de seu conteúdo.

Dito isso, entendemos ser urgente chamar a atenção para o fato de que essa proposta está imbricada de interesses específicos. Reconhecer tal intencionalidade é imprescindível para o debate e o fortalecimento de resistências a esse processo.

Tomando as problematizações expostas, levantamos outros questionamentos em relação ao que é, afinal, uma escola sem partido: O que é a escola, senão o espaço ocupado pelos diferentes movimentos e relações que estabelecemos com o seu "dentrofora"? Seria possível atravessar os muros das escolas sem minhas opiniões e convicções? Seria possível não "transmitir" minhas ideias, se elas me atravessam e engendram meus discursos e corporeidade?

Acreditar nessas possibilidades e apostar em tal projeto é, por um lado, desconsiderar o processo intercomunicativo que se estabelece coletivamente, independente da vontade individual, e por outro - não tão visível - querer impor arbitrariamente as condições para a produção/construção de uma determinada concepção de sociedade.

Propor um projeto que pretende inserir, por meio de lei, "neutralidade" e “imparcialidade" nos espaços escolares é fazer "letra morta", estando já fadado ao fracasso. Com inúmeras escolas que há no Brasil com seus respectivos/as profissionais, existiria algum 
órgão ou instituição capaz de controlar/monitorar todas as aulas? Seria possível "assegurar" que as propostas curriculares prescritas se restrinjam somente aos conteúdos oficiais e determinados? Ou ainda, e muito mais difícil, que as composições curriculares que são tecidas e vividas cotidianamente nos diferentes espaços escolares sejam reguladas?

O que se percebe é que tal proposta está recheada de intencionalidades, carente de maturidade e de conhecimentos a respeito da realidade educacional. Além disso, se a educação escolar buscar na

[...] uniformidade e a univocidade curricular dispositivos de controle dos sujeitos, dos conhecimentos e dos processos de aprendizagemensino, ainda que se anuncie como sendo para todos, dificulta o percurso de muitos estudantes que se distanciam social ou culturalmente do modelo valorizado (ESTEBAN, 2012, p. 125).

Falta à proposta conhecimentos elementares para discutir a pauta da educação e sobra conservadorismo maniqueísta. É preciso conhecer as realidades das escolas e daqueles que as ocupam antes de propor qualquer tipo de mudança ou de melhoria. Qualquer proposta que emerja de um contexto arbitrário, em que se encontra ausente o aprofundamento de um debate coletivo e a composição e/ou produção de alternativas com todos os interessados, principalmente com aqueles que se encontram na ponta do processo, está fadada ao fracasso, independente de sua aprovação.

Infelizmente não é a primeira vez que nos deparamos com propostas/projetos que se intitulam necessárias e objetivam "regularizar" - ou mesmo "regular" - a educação brasileira. Projetos como esse fazem parte de uma realidade assombrosa em que muitos se aventuram como expert, procurando criticar e/ou fornecer receitas, na maioria das vezes, descontextualizadas das realidades em questão e sem a necessária discussão com os sujeitos que estão na ponta do processo educacional.

Contudo, sem a intenção de encerrarmos as discussões propostas e deixando/traçando uma linha de esperança em meio a tempos difíceis em que nos encontramos, em que a pergunta realizada por Bertolt Brech "Que tempos são esses em que temos que defender o óbvio?" continua viva, apostamos na ideia de que um corpo, quando doente, tende a lançar mão de todos os modos para continuar a viver. Nesse sentido, quem sabe esse "corpo" doente não seja o pensamento e/ou modo de expressão presente em determinadas forças que procuram assujeitar, escravizar e produzir existências serializadas e universalizantes, que por estar ameaçado esteja produzindo mecanismos para sobreviver e/ou se fortalecer. 


\section{Considerações finais}

Operar por dualidades constitui uma herança do pensamento moderno ainda bastante comum em nosso tempo. Muito embora a realidade nos esteja dando mostras de que tal operação apresenta sérias limitações, esta tem predominado em diferentes formas de análise e de tratamento de questões ligadas ao campo educacional, como a própria arquitetura das escolas, cujos muros e cercas procuram "protegê-la" - ou isolá-la - daquilo que é considerado nocivo da/na sociedade.

De forma semelhante, no campo do conhecimento, uma determinada "engenharia curricular" também é criada/desenvolvida na tentativa de "garantir" que determinados conhecimentos, produzidos por grupos sociais específicos sejam considerados legítimos e prevaleçam em detrimento de tantos outros.

A problematização que procuramos estabelecer ao longo deste artigo vai ao encontro do pensamento que considera escola e sociedade como espaços que se atravessam em contínuo, ininterruptamente, cujas dinâmicas são interdependentes e constitutivas.

Outra consideração que fazemos é quanto à ideia de uma escola "neutra". Essa concepção, em nosso entender, é bastante perturbadora e, ao mesmo tempo, curiosa, pois, se por um lado representa um certo romantismo ou mesmo ingenuidade ao se acreditar que nela podem se processar movimentos imunes e/ou descolados do fervilhar de outros planos do cotidiano social, por outro pode também representar uma ideia imbuída de interesses que se propõe a desmobilização e desconstrução da produção de uma criticidade que, de certa maneira, vinha sendo produzida nos espaços escolares.

A liberdade para se discutir determinadas relações sociais, sejam de dominação, exclusão, subordinação e/ou repressão em diferentes dimensões da vida, poderá ser colocada sobre uma "peneira" arbitrária; determinados "temas" ficariam relegados à "rua", não devendo/podendo fazer parte das discussões "colegiais", para não impregnar ou contaminar a "pureza" ou a "imaturidade" das mentes pensantes do corpo discente.

Nas narrativas dos representantes da "Escola sem Partido", a idealização do projeto seria uma maneira de não ideologizar o campo educacional/escolar com determinadas perspectivas político-sociais que pudessem “induzir" ou "persuadir” o corpo discente.

No entanto, o que se percebe é um movimento conservador e intencional de despolitização por parte de determinados grupos, cujos interesses ficam cada vez mais evidentes quando se observa o histórico e os movimentos de seus envolvidos, cujo objetivo é estabelecer uma mordaça conveniente à permanência do status quo 
Frente a essa "verdade" conservadora e excludente que procura cercear a liberdade e a criticidade justamente num espaço em que tais práticas são indispensáveis, cabe não somente aos profissionais que lidam e/ou labutam nesses espaços, mas como também à própria sociedade, na medida em que vê a educação de crianças, adolescentes e/ou jovens tolhida de aspectos fundamentais à formação cidadã, criarem formas de resistências e de recusa a tamanha incongruência.

Recusar é um passo importante. Lançar mão de diferentes recursos e instrumentos, como a própria constituição e outras legislações vigentes que asseguram a liberdade de expressão e de pensamento - uma liberdade conquistada que, nos últimos tempos, se vê ameaçada - se constitui como importante instrumento de luta e de fortalecimento da democracia.

O momento/tempo em que nos situamos requer atenção. Acreditamos que, como sujeitos que compõem a história e o espaço-tempo da comunidade escolar em que estamos e atuamos, precisamos, no mínimo, nos fazer ser ouvidos/as e assumir o protagonismo da profissão nos espaços em que nos situamos. Basta de imposições e de determinações que não dialogam com todos os sujeitos envolvidos. A escola, assim como a vida, é constituída por múltiplos atravessamentos e diferentes movimentos incapazes de serem inertizados/estancados. A resistência aos assujeitamentos, que nos são impostos, corresponde a uma tarefa constante! E isso é um partido a ser assumido.

\section{Referências}

ALVES, Nilda. Currículo: conhecimento e cultura. Entrevista concedida ao programa Salto para o Futuro. Realizada em 30/10/2008. Disponível em: < http://www.tvbrasil.org.br/saltoparaofuturo/entrevista.asp?cod_Entrevista=54 >. Acesso em: 27/01/2015.

ALVES, Nilda. A Compreensão de Políticas nas Pesquisas com os Cotidianos: Para Além dos Processos de Regulação. Educ. Soc., Campinas, v. 31, n. 113, p. 1195-1212, out.-dez. 2010. Acesso em: 27/01/2015. Disponível em: http://www.cedes.unicamp.br

CARVALHO, Janete Magalhães. Do projeto às estratégias/táticas dos professores como profissionais necessários aos espaços/tempos da escola pública brasileira. In: CARVALHO, Janete Magalhães (org.). Diferentes perspectivas da profissão docente na atualidade. 2 . Ed. Vitória: Edufes, 2004.

ESTEBAN, Maria Teresa. Currículos e conhecimentos escolares. In: FERRAÇO, Carlos Educardo e CARVALHO, Janete Magalhães (Org.). Currículos, pesquisas, conhecimentos e produções de subjetividades. Petrópolis: DP ey Alii; Vitória: Nupec/Ufes, 2013. 
GARCIA, Regina Leite; ALVES, Nilda. Para começo de conversa. In: GARCIA, Regina Leite; ALVES, Nilda (Org.). O Sentido da Escola. 5. ed. Petrópolis: DP ey Alii, 2008.

ILLICH, Ivan. Sociedade sem escolas. Tradução de Lúcia Mathilde Endlich Orth. $7^{a}$ Ed. Petrópolis, Vozes, 1985.

MATURANA, Humberto. Emoções e linguagem na educação e na política; Tradução: José Fernando Campos Fontes. $1^{a}$ ed. atualizada. - Belo Horizonte: Editora. UFMG, 2009.

MORIN, Edgar. $O$ método 4 - As ideias: a sua natureza, vida, habitat e organização. Tradução de Emilio Campos Lima. Mem Martins Codex: Editions du Seiul, 1991.

MORIN, Edgar. O método 1: A Natureza da Natureza. 3. ed. Porto Alegre: Sulina, 2013.

SANTOS, Boaventura de Sousa. Um discurso sobre as ciências. 16. ed. Porto:

Afrontamentos, 2010. 